Research Article

\title{
Bending of Symmetric Sandwich FGM Beams with Shear Connectors
}

\author{
Dung Nguyen Thai $\mathbb{D}^{1},{ }^{1}$ Phung Van Minh $\mathbb{D}^{1},{ }^{1}$ Cuong Phan Hoang $\mathbb{D},{ }^{2}$ Tam Ta Duc $\mathbb{D}^{1},{ }^{1}$ \\ Nhung Nguyen Thi Cam $\mathbb{D}^{1},{ }^{1}$ and Dung Nguyen Thi $\mathbb{1}^{1}$
}

${ }^{1}$ Faculty of Special Equipment, Le Quy Don Technical University, Hanoi 100000, Vietnam

Correspondence should be addressed to Phung Van Minh; minhpv.mta@gmail.com

Received 10 May 2021; Revised 16 June 2021; Accepted 29 June 2021; Published 8 July 2021

Academic Editor: Hui Wang

Copyright (c) 2021 Dung Nguyen Thai et al. This is an open access article distributed under the Creative Commons Attribution License, which permits unrestricted use, distribution, and reproduction in any medium, provided the original work is properly cited.

\begin{abstract}
This paper carries out the static bending analysis of symmetric three-layer functionally graded sandwich beams, in which each layer is made from different functionally graded materials, and they are connected by shear connectors due to sliding movement. The finite element formulations are based on Timoshenko's first-order shear deformation beam theory (FSDT) and the finite element method to establish the equilibrium equation of beams. The calculation program is coded in the MATLAB environment, and then verification examples are given out to compare the numerical data of present work with those of exact open sources. The impact of several geometrical and material parameters on the mechanical response of the structure, such as the height-to-length ratio, boundary conditions, volume fraction index, and especially the shear coefficient of connectors, is being explored. When designing and using these types of structures in engineering practice, the computed results can be utilized as a valid reference.
\end{abstract}

\section{Introduction}

Recently, functionally graded materials (FGM) have been widely used in engineering practice due to their good performance, such as high strength, toughness, and wear resistance [1-5]. In particular, they can remove the delamination and stress jumping phenomena among layers, which normally occur in conventional composite structures. There is a huge range of publications dealing with FGM structures by scientists worldwide [6-11]. Mechanical structures tend to be intergraded into one complicated system to meet high requirements. Therefore, to analyze the mechanical responses of smart material structures, many shear deformation theories have been developed. In addition, beam structures are one of the most common elements in any field of engineering practice. Thus, investigations of smart beam structures are still a challenge for scientists.

This paper aims to carry out the static bending analysis of symmetric FGM sandwich beams with shear connectors, where the top and bottom layers are made from FG materials, and the core layer is made from metal, the same as in the two outer layers. These types of structures are commonly used in civil engineering, aircraft, nuclear plants, and so on. For example, in composite beam design, headed stud shear connectors are commonly used to transfer longitudinal shear forces across the steel-concrete interface. However, at first, a short review relating to this proposed problem was summed up. Lam and El-Lobody [12] studied the mechanical behavior of head stud shear connectors in the composite beam. In addition, an effective numerical model used the finite element method to simulate the pushoff test. The parametric studies using this model were performed to explore the variations in concrete strength and shear stud diameter. Shim et al. [13] carried out the push-out tests on large stud shear connectors, beyond the limits of proposed design codes. The static response was examined, and comparisons with design equations were conducted. Shear coefficients of the connectors in an elastic state and trilinear load-slip curves were presented from shear tests on 25, 27, and $30 \mathrm{~mm}$ studs. Salari et al. [14] presented 
a nonlinear analysis of composite beams with deformable shear connectors. The fundamental governing formulations were introduced for a composite beam with deformable shear connectors with small displacements. Based on established equations, a new composite beam element was modified by using the force method of analysis. The efficiency of the new element was compared with that of a previously modified displacement-based composite beam element. Gattesco and Giurianib [15] carried out an experimental study on stud shear connectors subjected to a cyclic load. The test was employed to explore the response of the shear connectors in four specimens: two of the four specimens were subjected to monotonically increasing loading, and the others were subjected to cyclic load. The experimental results of monotonic tests were compared with those obtained with a standard push-out test and showed a very good agreement. Roberts and Dogan [16] investigated the fatigue of welded stud shear connectors in steel-concrete-steel sandwich beam structures. Through the experimental results, they showed that the fatigue strength of the stud connectors, specified by the beam tests, was significantly higher than that determined by the push shear tests, as well as by the EC3 S-N curve. Weichen et al. [17] conducted thirty push-out tests on stud shear connectors to examine the influences of concrete strength, stud diameter and height, transverse reinforcement, stud welding technique, load versus slip curve, and the shear bearing capacity. Based on the experimental results, the stud shear mechanism was studied. A calculation model of stud shear bearing capacity was proposed, taking the effects of stud diameter and height, material strength, and elastic modulus into the analysis. Baran and Topkaya [18] experimentally carried out a study on European channel shear connectors. Besides, functionally graded materials, for example, which have varying microstructures from one material to another one and the size of the microstructures involved ranges typically over several orders of magnitude, may not be adequately modeled by employing classical continuum mechanics alone but are probably more accurately analyzed using nonclassical continuum mechanics, as well as using spatial variation of material properties [19]. Hachemi et al. [20] proposed higher-order shear and normal deformation theories to study the static bending of functionally graded plates, which reduced the number of unknowns and governing equations in the current methodology, making it easier to use. The position of the neutral surface was identified, and the governing steadiness equations based on the neutral surface were created using the enhanced shear and normal deformation theory. On the basis of a new theory of refined trigonometric shear deformation, Chikr et al. [21] explored the buckling analysis of material sandwich plates based on a two-parameter elastic foundation under various boundary circumstances. Then, utilizing revised shear deformation theory, Menasria et al. [22] offered a dynamic analysis of the FG-sandwich plate resting on elastic foundation with various types of support. The proposed analytical model has been simplified, and the number of unknowns has been reduced. Without any correction factors, zero-shear stress on the free surfaces of the FG-sandwich plate is guaranteed.

Recently, the mechanical responses of multilayered structures have been modified to account for the relative movement of the layers. Nam et al. [23] introduced a new efficient modified first-order shear model for static bending and vibration responses of the two-layer plate. Santos et al. [24] presented a finite element model for bolted shear connectors in concrete-filled steel tubular columns. Vetturayasudharsanan et al. [25] carried out an analytical study of triangular perfobond shear connectors. Xu et al. [26] published a book about the effect of concrete cracks on the corrosion of stud shear connectors. Arévalo et al. [27] presented the structural performance of steel angle shear connectors with different orientations. Hirane et al. [28] introduced a new $C^{0}$ higher-order layerwise finite element model for static and free vibration analysis of FGM sandwich plates. The suggested layerwise model for multilayer composite plates assumed a higher-order displacement field for the core and a first-order displacement field for the face sheets while ensuring displacement continuity in the layer. In contrast to traditional layerwise models, the current one has the advantage of having a constant number of variables that does not grow as the number of layers increases.

As can be seen, investigations of structures with shear connectors continue to play an important role in civil engineering, as well as other fields. As a result, in order to contribute to our understanding of the mechanical response of these types of structures, this paper will perform a static bending analysis of symmetric three-layer FGM sandwich beams with shear connectors by using the finite element method and the simple first-order shear deformation theory. The proposed problem was never mentioned and was not taken into account in any published studies.

The rest of this paper is organized as follows. The proposed model, assumptions, and finite element formulations are presented in detail in Section 2. Verification examples are introduced in the next section to evaluate the accuracy of the proposed mechanical model, as well as the calculation program. Then, a parameter study is conducted in this section to evaluate the influence of some geometrical and material properties on the static response of the beam. Finally, Section 4 sums up the novel points of this work.

\section{Finite Element Formulations}

2.1. The Model of the Symmetric FGM Sandwich Beam. Consider a symmetric FGM sandwich beam as shown in Figure 1.

The beam is formed from three single components (layers 1, 2, and 3) by shear connectors, in which layer 2 is the homogeneous metallic material, and layers 1 and 3 are made from the same functionally graded material, where the simple power-law distribution is used for describing the volume fraction of the ceramic $\left(V_{c}^{(i)}\right)$ and the metal $\left(V_{m}^{(i)}\right)$ in the $i$-th layer $(i=1,3)$ as follows [29-32]: 


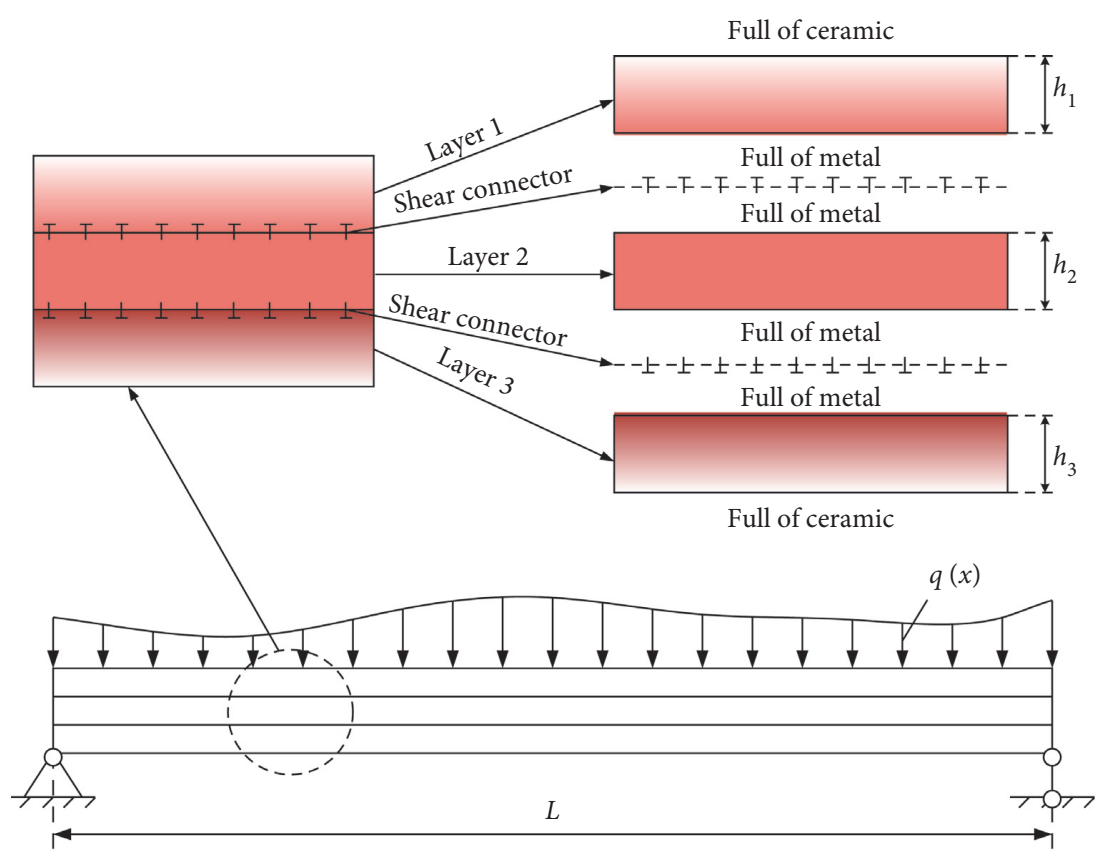

Figure 1: Model of symmetric FGM sandwich beam.

Layer $1=\left\{\begin{array}{l}V_{c}^{(1)}=\left(\frac{1}{2}+\frac{z^{(1)}}{h_{1}}\right)^{n_{1}}, \quad-0.5 h_{1} \leq z^{(1)} \leq 0.5 h_{1} \\ V_{m}^{(1)}=1-V_{c}^{(1)}\end{array}\right.$

Layer $3=\left\{\begin{array}{l}V_{m}^{(3)}=\left(\frac{1}{2}+\frac{z^{(3)}}{h_{3}}\right)^{n_{3}}, \quad-0.5 h_{3} \leq z^{(3)} \leq 0.5 h_{3} \\ V_{c}^{(3)}=1-V_{m}^{(3)}\end{array}\right.$

where $h_{1}, h_{2}$, and $h_{3}$ are the thickness of layers 1,2 , and 3 see Figure 1, respectively; $n_{1}$ and $n_{3}$ are the volume fraction indexes of layers 1 and 3 , respectively; $z_{1}$ and $z_{3}$ are the thickness coordinate variables of layers 1 and 3 ; and the subscripts $c$ and $m$ represent the ceramic and metal constituents, respectively.

In this study, the material properties such as the elastic modulus $E$ and Poisson's ratio $v$ can be followed by the rules of the mixture as [32-34]

$$
P^{(i)}\left(z^{(i)}\right)=P_{m}^{(i)}+\left(P_{c}^{(i)}-P_{m}^{(i)}\right) V_{c}^{(i)}
$$

where $P^{(i)}$ is the material properties of the $i$-th layer.
2.2. Governing Equations. An element model and the degrees of freedom at each node are shown in Figure 2.

In this study, some assumptions are used as follows:

(i)All materials work in the elastic limitation

(ii) Neglecting the mass of shear connectors

(iii) The external forces act perpendicularly at the top surface of the beam

(iv) There is no delamination phenomenon among the layers, and they only slide into each other

Herein, a two-node element with seven degrees of freedom (DOF) in each node is employed. According to the well-known Timoshenko beam theory [35], the displacement field of any point in a single beam is expressed as follows:

$$
\left\{\begin{array}{l}
u^{(i)}=u_{0}^{(i)}+z^{(i)} \cdot \varphi_{x}^{(i)} \\
w^{(i)}=w_{0}^{(i)}=w_{0}
\end{array}, \quad(i=1-3),\right.
$$

where $u_{0}^{(i)}$ and $w_{0}^{(i)}$ are the displacement components at the mid-axis of the beam in the $x^{(i)}$ and $z^{(i)}$ directions, respectively. $\varphi_{x}^{(i)}$ is the transverse normal rotation around the $y^{(i)}$-axis.

The relative movement vector between two layers at the contact line is calculated using the following equations:

$$
\left\{u_{\text {relative }}\right\}=\left\{\begin{array}{l}
u_{12} \\
u_{23}
\end{array}\right\}=\left\{\begin{array}{l}
u^{(1)}\left(-\frac{h_{1}}{2}\right)-u^{(2)}\left(\frac{h_{2}}{2}\right) \\
u^{(2)}\left(-\frac{h_{2}}{2}\right)-u^{(3)}\left(\frac{h_{3}}{2}\right)
\end{array}\right\}=\left\{\begin{array}{l}
\left(u_{0}^{(1)}-u_{0}^{(2)}\right)-\left(\frac{h_{1}}{2} \cdot \varphi_{x}^{(1)}+\frac{h_{2}}{2} \cdot \varphi_{x}^{(2)}\right) \\
\left(u_{0}^{(2)}-u_{0}^{(3)}\right)-\left(\frac{h_{2}}{2} \cdot \varphi_{x}^{(2)}+\frac{h_{3}}{2} \cdot \varphi_{x}^{(3)}\right)
\end{array}\right\} .
$$




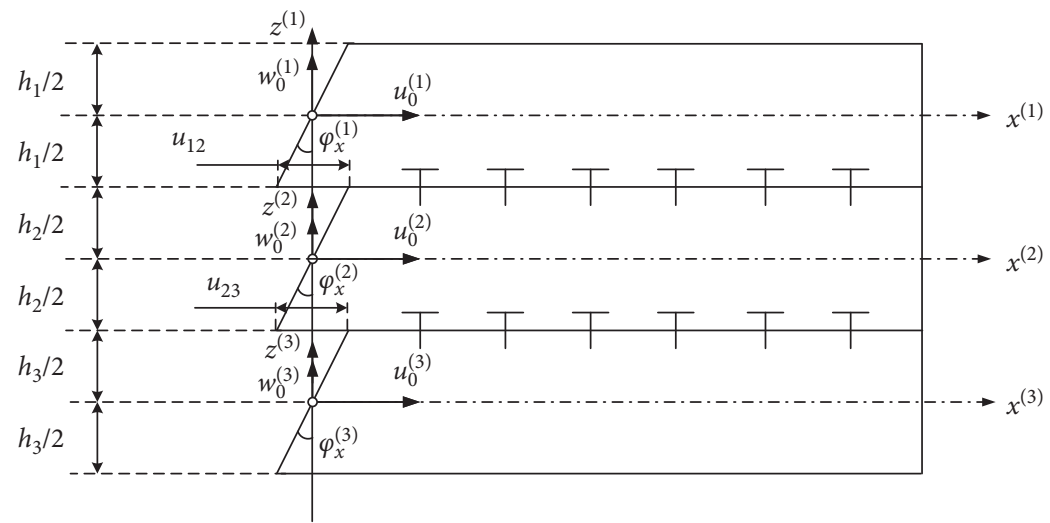

FIgURE 2: The element model of the beam.

The bending strain field of each layer is defined as follows:

$$
\varepsilon_{b}^{(i)}=\frac{\partial u^{(i)}}{\partial x}=\frac{\partial u_{0}^{(i)}}{\partial x}+z^{(i)} \cdot \frac{\partial \varphi_{x}^{(i)}}{\partial x}=\varepsilon_{m}^{(i)}+z^{(i)} \cdot \kappa^{(i)}, \quad(i=1-3),
$$

where $\varepsilon_{m}^{(i)}$ is the membrane bending strain and $\kappa^{(i)}$ is the curvature of layer $i$-th.

The shear strain field of each layer is defined as follows:

$$
\varepsilon_{s}^{(i)}=\gamma_{\mathrm{xz}}^{(i)}=\frac{\partial u^{i}}{\partial z^{(i)}}+\frac{\partial w^{(i)}}{\partial x}=\varphi_{x}^{(i)}+\frac{\partial w_{0}}{\partial x} ; \quad(i=1-3) .
$$

The normal stress of each layer is defined as follows:

$$
\left\{\begin{array}{l}
\sigma_{b}^{(1)}=E^{(1)}\left(z^{(1)}\right) \cdot \varepsilon_{b}^{(1)}=E^{(1)}\left(z^{(1)}\right) \cdot\left(\varepsilon_{m}^{(1)}+z^{(1)} \cdot \kappa^{(1)}\right), \\
\sigma_{b}^{(2)}=E^{(2)} \cdot \varepsilon_{b}^{(2)}=E^{(2)} \cdot\left(\varepsilon_{m}^{(2)}+z^{(2)} \cdot \kappa^{(2)}\right), \\
\sigma_{b}^{(3)}=E^{(3)}\left(z^{(2)}\right) \cdot \varepsilon_{b}^{(3)}=E^{(3)}\left(z^{(3)}\right) \cdot\left(\varepsilon_{m}^{(3)}+z^{(3)} \cdot \kappa^{(3)}\right) .
\end{array}\right.
$$

Equation (8) can be expressed as a matrix as follows:

$$
\left\{\sigma_{b}\right\}=\left[D_{b}\right]\left\{\varepsilon_{m}\right\}+\left[D_{b}\right] \cdot[Z] \cdot\{\kappa\},
$$

in which $\left\{\sigma_{b}\right\}=\left\{\begin{array}{lll}\sigma_{b}^{(1)} & \sigma_{b}^{(2)} & \sigma_{b}^{(3)}\end{array}\right\}^{T},\left\{\varepsilon_{m}\right\}=\left\{\begin{array}{lll}\varepsilon_{m}^{(1)} & \varepsilon_{m}^{(2)} & \varepsilon_{m}^{(3)}\end{array}\right\}^{T}$ and $\{\kappa\}=\left\{\begin{array}{lll}\kappa^{(1)} & \kappa^{(2)} & \kappa^{(3)}\end{array}\right\}^{T}$ are the normal stress vector, the bending membrane strain vector, and the curvature vector, respectively. $\left[D_{b}\right]$ and $[Z]$ are the bending material matrix and the coordinate variable matrix, which are written in the following matrix forms:

$$
\begin{aligned}
{\left[D_{b}\right] } & =\left[\begin{array}{ccc}
E^{(1)}\left(z^{(1)}\right) & 0 & 0 \\
0 & E^{(2)} & 0 \\
0 & 0 & E^{(3)}\left(z^{(3)}\right)
\end{array}\right], \\
{[Z] } & =\left[\begin{array}{ccc}
z^{(1)} & 0 & 0 \\
0 & z^{(2)} & 0 \\
0 & 0 & z^{(3)}
\end{array}\right] .
\end{aligned}
$$

The shear stress of each layer is defined as follows:

$$
\left\{\begin{array}{l}
\tau^{(1)}=\frac{E^{(1)}\left(z^{(1)}\right)}{2\left(1+\mu^{(1)}\left(z^{(1)}\right)\right)} \cdot \varepsilon_{s}^{(1)}=\frac{E^{(1)}\left(z^{(1)}\right)}{2\left(1+\mu^{(1)}\left(z^{(1)}\right)\right)} \cdot \gamma_{x z}^{(1)}, \\
\tau^{(2)}=\frac{E^{(2)}}{2\left(1+\mu^{(2)}\right)} \cdot \varepsilon_{s}^{(1)}=\frac{E^{(2)}}{2\left(1+\mu^{(2)}\right)} \cdot \gamma_{x z}^{(2)}, \\
\tau^{(3)}=\frac{E^{(3)}\left(z^{(3)}\right)}{2\left(1+\mu^{(3)}\left(z^{(3)}\right)\right)} \cdot \varepsilon_{s}^{(3)}=\frac{E^{(3)}\left(z^{(3)}\right)}{2\left(1+\mu^{(3)}\left(z^{(3)}\right)\right)} \cdot \gamma_{x z}^{(3)},
\end{array}\right.
$$

Note that, in equation (10), $\mu^{(i)}(i=1-3)$ is Poisson's ratio of layer $i$-th.

Equation (10) can be expressed as a matrix as follows:

$$
\{\tau\}=\left\{\tau^{(1)} \tau^{(2)} \tau^{(3)}\right\}^{T}=\left[D_{s}\right]\left\{\varepsilon_{s}\right\}
$$

where $\left\{\varepsilon_{s}\right\}=\left\{\begin{array}{lll}\varepsilon_{s}^{(1)} & \varepsilon_{s}^{(2)} & \varepsilon_{s}^{(3)}\end{array}\right\}^{T}$ is the shear strain vector. $\left[D_{s}\right]$ is the shear material matrix, which is expressed in the following form:

$$
\left[D_{s}\right]=\left[\begin{array}{ccc}
\frac{E^{(1)}\left(z^{(1)}\right)}{2\left(1+\mu^{(1)}\left(z^{(1)}\right)\right)} & 0 & 0 \\
0 & \frac{E^{(2)}}{2\left(1+\mu^{(2)}\right)} & 0 \\
0 & 0 & \frac{E^{(3)}\left(z^{(3)}\right)}{2\left(1+\mu^{(3)}\left(z^{(3)}\right)\right)}
\end{array}\right] .
$$

The membrane force per unit length of each layer is calculated as follows: 


$$
\left\{\begin{array}{l}
N^{(1)}=\int_{-h_{1} / 2}^{h_{1} / 2} \sigma_{b}^{(1)} \cdot z^{(1)}=\int_{-h_{1} / 2}^{h_{1} / 2} E^{(1)}\left(z^{(1)}\right) \cdot \varepsilon_{b}^{(1)} \cdot \mathrm{d} z^{(1)}, \\
N^{(2)}=\int_{-h_{2} / 2}^{h_{2} / 2} \sigma_{b}^{(2)} \cdot \mathrm{d} z^{(2)}=\int_{-h_{2} / 2}^{h_{2} / 2} E^{(2)} \cdot \varepsilon_{b}^{(2)} \cdot \mathrm{d} z^{(2)}, \\
N^{(3)}=\int_{-h_{3} / 2}^{h_{3} / 2} \sigma_{b}^{(3)} \cdot \mathrm{d} z^{(3)}=\int_{-h_{3} / 2}^{h_{3} / 2} E^{(3)}\left(z^{(3)}\right) \cdot \varepsilon_{b}^{(3)} \cdot \mathrm{d} z^{(3)} .
\end{array}\right.
$$

Equation (13) may therefore be expressed as a matrix:

$$
\{N\}=[A] \cdot\left\{\varepsilon_{m}\right\}+[B] \cdot\{\kappa\},
$$

where $\{N\}=\left\{N^{(1)} N^{(2)} \quad N^{(3)}\right\}^{T}$ is the membrane force vector (per unit length). $[A]$ and $[B]$ can be seen in Appendix.

Each layer's bending moment per unit length is determined using the following equation:

$$
\left\{\begin{array}{l}
M^{(1)}=\int_{-h_{1} / 2}^{h_{1} / 2} \sigma_{b}^{(1)} \cdot z^{(1)} \cdot \mathrm{d} z^{(1)}=\int_{-h_{1} / 2}^{h_{1} / 2} E^{(1)}\left(z^{(1)}\right) \cdot \varepsilon_{b}^{(1)} \cdot z^{(1)} \mathrm{d} z^{(1)} \\
M^{(2)}=\int_{-h_{2} / 2}^{h_{2} / 2} \sigma_{b}^{(2)} \cdot z^{(2)} \cdot \mathrm{d} z^{(2)}=\int_{-h_{2} / 2}^{h_{2} / 2} E^{(2)} \cdot \varepsilon_{b}^{(2)} \cdot z^{(2)} \cdot \mathrm{d} z^{(2)} \\
M^{(3)}=\int_{-h_{3} / 2}^{h_{3} / 2} \sigma_{b}^{(3)} \cdot z^{(3)} \cdot \mathrm{d} z^{(3)}=\int_{-h_{3} / 2}^{h_{3} / 2} E^{(3)}\left(z^{(3)}\right) \cdot \varepsilon_{b}^{(3)} \cdot z^{(3)} \cdot \mathrm{d} z^{(3)}
\end{array}\right.
$$

Similarly, equation (15) may be expressed as a matrix:

$$
\{M\}=[B] \cdot\left\{\varepsilon_{m}\right\}+[D] \cdot\{\kappa\},
$$

in which $\{M\}=\left\{M^{(1)} M^{(2)} M^{(3)}\right\}^{T}$ is the bending moment vector (per unit length). [D] can be found in Appendix, too.

The shear force per unit length of each layer is defined as follows:

$$
\left\{\begin{array}{l}
Q^{(1)}=k \int_{-h_{1} / 2}^{h_{1} / 2} \tau^{(1)} \cdot \mathrm{d} z^{(1)}=k \int_{-h_{1} / 2}^{h_{1} / 2} \frac{E^{(1)}\left(z^{(1)}\right)}{2\left(1+\mu^{(1)}\left(z^{(1)}\right)\right)} \cdot \varepsilon_{s}^{(1)} \cdot \mathrm{d} z^{(1)} \\
Q^{(2)}=k \int_{-h_{2} / 2}^{h_{2} / 2} \tau^{(2)} \cdot \mathrm{d} z^{(2)}=k \int_{-h_{2} / 2}^{h_{2} / 2} \frac{E^{(2)}}{2\left(1+\mu^{(2)}\right)} \cdot \varepsilon_{s}^{(2)} \cdot \mathrm{d} z^{(2)} \\
Q^{(3)}=k \int_{-h_{3} / 2}^{h_{3} / 2} \tau^{(3)} \cdot \mathrm{d} z^{(3)}=k \int_{-h_{3} / 2}^{h_{3} / 2} \frac{E^{(3)}\left(z^{(3)}\right)}{2\left(1+\mu^{(3)}\left(z^{(3)}\right)\right)} \cdot \varepsilon_{s}^{(3)} \cdot \mathrm{d} z^{(3)}
\end{array}\right.
$$

Because the Timoshenko beam theory is being utilized here, a shear correction factor of $k=5 / 6$ must be added to equation (17), which may now be expressed in matrix form as

$$
\{Q\}=[\widehat{A}] \cdot\left\{\varepsilon_{s}\right\},
$$

where $\{Q\}$ is the shear force (per unit length) vector. The matrix $[\widehat{A}]$ is placed in Appendix.

Now, equations (14), (16), and (18) are written in the following matrix form:

$$
\left\{\begin{array}{c}
\{N\} \\
\{M\} \\
\{Q\}
\end{array}\right\}=\left[\begin{array}{ccc}
{[A]} & {[B]} & 0 \\
{[B]} & {[D]} & 0 \\
0 & 0 & {[\widehat{A}]}
\end{array}\right]\left\{\begin{array}{c}
\left\{\varepsilon_{m}\right\} \\
\{\kappa\} \\
\left\{\varepsilon_{s}\right\}
\end{array}\right\} .
$$

Next, the strain energy potential of the beam element is calculated as follows [10]:

$$
U_{1}=\frac{1}{2} \int_{S_{e}}\{\varepsilon\}^{T}\{\sigma\} \mathrm{d} S_{e}=\frac{1}{2} \int_{L_{e}}\left(\int_{-h_{i} / 2}^{h_{i} / 2}\{\varepsilon\}^{T}\{\sigma\} \mathrm{d} z^{(i)}\right) \mathrm{d} x, \quad(i=1-3)
$$

in which $L_{e}$ is the length of the beam element. Then, by integrating equation (20), the expanding form is obtained as follows [10]:

$$
\begin{aligned}
U_{1}= & \frac{1}{2} \int_{L_{e}}\left(\left\{\varepsilon_{m}\right\}^{T}[A]\left\{\varepsilon_{m}\right\}+\left\{\varepsilon_{m}\right\}^{T} \cdot[B] \cdot\{\kappa\}\right. \\
& \left.+\{\kappa\}^{T}[B]\left\{\varepsilon_{m}\right\}+\{\kappa\}^{T}[D]\{\kappa\}+\left\{\varepsilon_{s}\right\}^{T}[\widehat{A}]\left\{\varepsilon_{s}\right\}\right) \mathrm{d} x .
\end{aligned}
$$

Herein, a 2-node beam element is employed, where each node includes seven degrees of freedom (see Figure 2), so the total degrees of freedom of each element are defined as

$$
\begin{aligned}
& \left\{q_{e}\right\}=\left\{\begin{array}{l}
\left\{q_{1}\right\} \\
\left\{q_{2}\right\}
\end{array}\right\}, \\
& \left\{q_{j}\right\}=\left\{\begin{array}{llllll}
u_{0 j}^{(1)} & u_{0 j}^{(2)} & u_{0 j}^{(3)} & w_{0 j} & \varphi_{x j}^{(1)} & \varphi_{x j}^{(2)}
\end{array} \varphi_{x j}^{(3)}\right\}^{T}, \quad(j=1-2) .
\end{aligned}
$$


The nodal displacement vector is interpolated from the nodal values as follows:

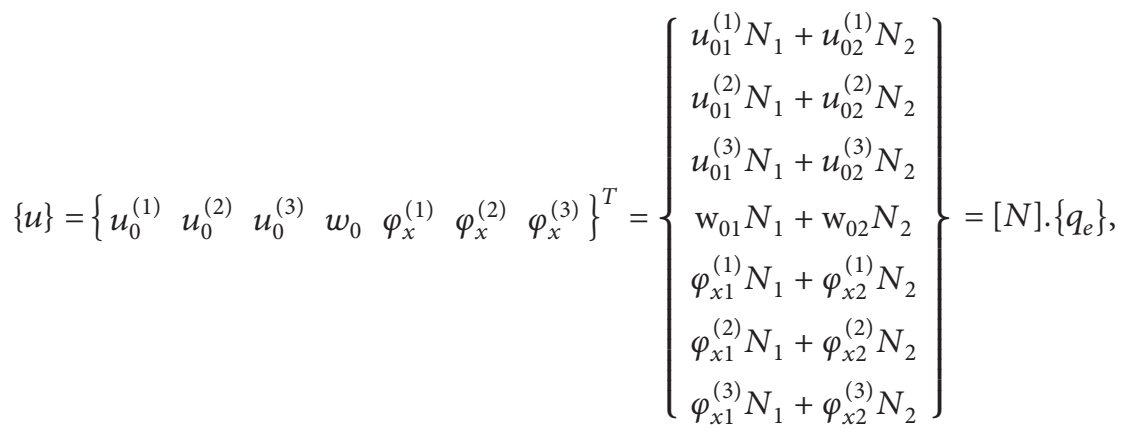

$$
\begin{aligned}
& K_{e}^{1}=\int_{L_{e}}\left(\left[B_{1}\right]^{T} \cdot[A] \cdot\left[B_{1}\right]+\left[B_{1}\right]^{T} \cdot[B] \cdot\left[B_{2}\right]\right. \\
& +\left[B_{2}\right]^{T} \cdot[B] \cdot\left[B_{1}\right]+\left[B_{2}\right]^{T} \cdot[D] \cdot\left[B_{2}\right] \\
& \left.+\left[B_{3}\right]^{T} \cdot[\widehat{A}] \cdot\left[B_{3}\right]\right) \mathrm{d} x,
\end{aligned}
$$

functions, and $[N]$ is the shape function matrix, which can be found in Appendix.

So the bending membrane strain vector, the curvature vector, and the shear strain vector can be transformed as

$$
\left\{\varepsilon_{m}\right\}=\left\{\begin{array}{l}
\frac{\partial u_{0}^{(1)}}{\partial x} \\
\frac{\partial u_{0}^{(2)}}{\partial x} \\
\frac{\partial u_{0}^{(3)}}{\partial x}
\end{array}\right\}=\left[\begin{array}{ccccccc}
\frac{\partial}{\partial x} & 0 & 0 & 0 & 0 & 0 & 0 \\
0 & \frac{\partial}{\partial x} & 0 & 0 & 0 & 0 & 0 \\
0 & 0 & \frac{\partial}{\partial x} & 0 & 0 & 0 & 0
\end{array}\right]\{u\}=\left[B_{1}\right] \cdot\left\{q_{e}\right\},
$$

$\{\kappa\}=\left\{\begin{array}{c}\frac{\partial \varphi_{x}^{(1)}}{\partial x} \\ \frac{\partial \varphi_{x}^{(2)}}{\partial x} \\ \frac{\partial \varphi_{x}^{(3)}}{\partial x}\end{array}\right\}=\left[\begin{array}{ccccccc}0 & 0 & 0 & 0 & \frac{\partial}{\partial x} & 0 & 0 \\ 0 & 0 & 0 & 0 & 0 & \frac{\partial}{\partial x} & 0 \\ 0 & 0 & 0 & 0 & 0 & 0 & \frac{\partial}{\partial x}\end{array}\right]\{u\}=\left[B_{2}\right]\left\{q_{e}\right\}$,

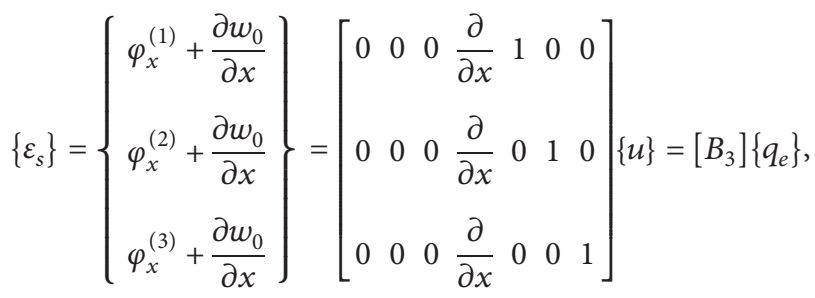

where $\left[B_{1}\right],\left[B_{2}\right]$ and $\left[B_{3}\right]$ are the differential shape function matrices, and all of them can be seen in detail in Appendix.

Substituting equations (24)-(26) into equation (21), the element stiffness matrix without taking into account shear connectors is obtained as follows:
For the role of shear connectors, their strain energy is calculated as follows [9]:

$$
U_{2}=\frac{1}{2} \int_{S_{e}}\left\{u_{\text {relative }}\right\}^{T} \cdot\left[K_{\text {relative }}\right] \cdot\left\{u_{\text {relative }}\right\} \cdot \mathrm{d} S_{e},
$$

in which $\left[K_{\text {relative }}\right]=\left[\begin{array}{cc}K_{12} & 0 \\ 0 & K_{23}\end{array}\right]$ is the shear coefficient matrix of shear connectors; $K_{12}$ is the shear coefficient of layers 1 and 2; $K_{23}$ is the shear coefficient of layers 2 and 3; see Figure 1. External forces will cause sliding movement between the layers. Thus, the shear connections will have to provide work to counteract the impacts of external forces.

In addition, the relative movement vector $u_{\text {relative }}$ can be expanded similarly to equations (24)-(26) as follows:

$$
\begin{aligned}
\left\{u_{\text {relative }}\right\} & =\left\{\begin{array}{c}
\left(u_{0}^{(1)}-u_{0}^{(2)}\right)-\left(\frac{h_{1}}{2} \cdot \varphi_{x}^{(1)}+\frac{h_{2}}{2} \cdot \varphi_{x}^{(2)}\right) \\
\left(u_{0}^{(2)}-u_{0}^{(3)}\right)-\left(\frac{h_{2}}{2} \cdot \varphi_{x}^{(2)}+\frac{h_{3}}{2} \cdot \varphi_{x}^{(3)}\right)
\end{array}\right\} \\
& =\left[B_{\text {relative }}\right]\left\{q_{e}\right\},
\end{aligned}
$$

where

$\left[B_{\text {relative }}\right]=$

$\sum_{i=1}^{2}\left[\begin{array}{ccccccc}N_{i} & -N_{i} & 0 & 0 & -h_{1} / 2 \cdot N_{i} & -h_{2} / 2 \cdot N_{i} & 0 \\ 0 & N_{i} & -N_{i} & 0 & 0 & -h_{2} / 2 \cdot N_{i} & -h_{3} / 2 \cdot N_{i}\end{array}\right]$

Now, substituting equation (28) into equation (27), one gets

$$
K_{e}^{2}=\int_{L_{e}}\left(\left[B_{\text {relative }}\right]^{T} \cdot\left[K_{\text {relative }}\right] \cdot\left[B_{\text {relative }}\right]\right) \mathrm{d} x .
$$


Then, combining equation (27) with equation (29), the element stiffness matrix is obtained as follows:

$$
K_{\mathrm{e}}=K_{e}^{1}+K_{e}^{2}
$$

Consider an external distribution force $q(x)$ acting at the top surface of the beam; see Figure 1. Hence, by applying the principle of virtual work, the work done by an external force is obtained as follows [10]:

$$
W_{e}=\int_{L_{e}}\{u\}^{T}\{p\} \mathrm{d} x,
$$

where $\{p\}$ is the nodal force vector, which is expressed as follows:

$$
\{p\}=\left\{\begin{array}{lllllll}
0 & 0 & 0 & q(x) & 0 & 0 & 0
\end{array}\right\}^{T} .
$$

Substituting equation (32) into equation (31), one gets

$$
W_{e}=\left\{q_{e}\right\}^{T}\left(\int_{L_{e}}[N]^{T}\{p\} \mathrm{d} x\right)=\left\{q_{e}\right\}^{T}\left\{F_{e}\right\} .
$$

Now, the element nodal force vector is obtained as follows:

$$
\left\{F_{e}\right\}=\int_{L_{e}}[N]^{T}\{p\} \mathrm{d} x .
$$

After assembling the element stiffness matrix $\left[K_{e}\right]$ and the element force vector $\left\{F_{e}\right\}$, the global stiffness matrix $[K]$ and the global force vector $\{F\}$ are obtained.

For the static problem, the following equation is used $[9,10]$.

$$
\{F\}=[K] \cdot\{U\}
$$

in which $\{U\}$ is the global displacement vector of the structure.

\section{Numerical Results and Discussion}

3.1. Verification Examples. To begin, the authors carry out verification examples for static bending problems to ensure the accuracy of the computation program written in the MATLAB environment. Consider the present symmetric FGM sandwich beam under a uniformly distributed force $q(x)=104(\mathrm{~N} / \mathrm{m})$ (Figure 1) with geometric properties: the length of the beam $L=4 \mathrm{~m}$, the width of each layer $b_{1}=b_{2}=b_{3}=0.3 \mathrm{~m}$, and the height of each layer $h_{1}=h_{2}=h_{3}=0.05 \mathrm{~m}$. Layers 1 and 3 are made from the same functionally graded material $\left(\mathrm{Al} / \mathrm{Al}_{2} \mathrm{O}_{3}\right)$; layer 2 is made from a homogeneous metal ( $\mathrm{Al}$ ) with the material properties that are listed in Table 1.

Herein, $n=\infty$ is chosen in equation (1), and $n=0$ in equation (2), and the shear coefficient of shear connectors $K_{12}=K_{23}=\infty$ (this means there is no relative movement phenomenon among layers). Then, the present symmetric FGM sandwich beam becomes a homogeneous metal (Al) beam with a width of $b=b_{1}=b_{2}=b_{3}=0.3 \mathrm{~m}$, a height of $h=h_{1}+h_{2}+h_{3}=0.15 \mathrm{~m}$, and a length of $L=4 \mathrm{~m}$. Now, the data of these computed results with some exact solutions in open literature is compared as shown in Table 2.
Table 2 clearly shows that the computed results of this work and the exact solution agree extremely well. Hence, the proposed theory and calculation program have been verified and will be used to analyze the static bending problem. Figure 3 is the convergence rate of maximum deflection of a fully simply supported beam.

Readers can see in Figure 3 that when the beam is only divided into 12 elements, the obtained results are acceptable. So, for all the next explorations, the 12-element beam is used to save computation time.

\subsection{Parameter Study}

3.2.1. The Influence of the Length-to-Height Ratio. Now, let us consider a fully simply supported beam with the geometrical dimensions and the material properties as presented in the verification example: $b_{1}=b_{2}=b_{3}=0.3 \mathrm{~m}$, $h_{1}=h_{2}=h_{3}=0.05 \mathrm{~m}$, the volume fraction exponents of the top (layer (1)) and the bottom (layer (3)) layers $n_{1}=n_{3}=0.5$, while the core layer (layer (2)) is metal (Al). The shear coefficients of shear connectors $K_{12}=K_{23}=5 \cdot 10^{7} \mathrm{~N} / \mathrm{m}^{2}$. A uniform distribution force $q(x)=10^{4} \mathrm{~N} / \mathrm{m}$ is applied. The nondimensional maximum deflection of the beam is normalized as follows:

$$
w^{*}=\frac{100 E_{m} h^{3}}{q(x) L^{4}} w\left(\frac{L}{2}\right) .
$$

Change the length of the beam, so that the $L / h$ ratio gets the values of $15,20,25,30$, and 35 , respectively. The nondimensional maximum deflections of the beam are presented in Figure 4.

It can be seen that when the length-to-height ratio increases, the maximum deflection of the beam also increases. This can be explained by the length of the beam increasing, the beam becomes softer, and the structure will be weaker, while the other parameters remain as they are. As a result, the maximum deflection of the beam increases.

3.2.2. Effect of the Volume Fraction Index. This subsection is about investigating the effect of the volume fraction index of layers 1 and 3. Consider the three-meter, fully simple, supported beam shown in the preceding exploration. Herein, two cases of the volume fraction index are considered as follows:

(i) Case 1: the volume fraction index of layer 1, $n_{1}=5$, and one of the layers 2 ranges between 0 and 10 .

(ii) Case 2: the volume fraction index of layer $2, n_{2}=5$, as well as that of layer 1, ranges from 0 to 10 .

The nondimensional maximum deflection of the beam is normalized as shown in equation (37). The maximum deflection responses in the three cases are presented in Figure 5.

From Figure 5, it can be observed that when increasing the volume fraction index of the top and the bottom surface, the proportion of the metal in the beam increases, and that of 
TABLE 1: Material properties.

\begin{tabular}{lcc}
\hline Material & Young's modulus $E\left(\mathrm{~N} / \mathrm{m}^{2}\right)$ & Poisson's ratio $\mu$ \\
\hline $\mathrm{Al}$, metal & $70.10^{9}$ & 0.3 \\
$\mathrm{Al}_{2} \mathrm{O}_{3}$, ceramic & $380.10^{9}$ & 0.3 \\
\hline
\end{tabular}

TABle 2: Comparison results of maximum deflections.

\begin{tabular}{|c|c|c|c|}
\hline Boundary condition & & Maximum defection $(\mathrm{m})$ & Error (\%) \\
\hline CC & $\begin{array}{c}\text { This work } \\
11.4972 \times 10^{-4}\end{array}$ & $\begin{array}{c}\text { Exact formula }[36,37] w_{\max }=(1 / 384) \cdot\left(q(x) \cdot L^{4} / E_{m} I\right) \\
11.2874 \times 10^{-4}\end{array}$ & 1.8588 \\
\hline SS & $\begin{array}{c}\text { This work } \\
56.6340 \times 10^{-4}\end{array}$ & $\begin{array}{c}\text { Exact formula }[36,37] w_{\max }=(5 / 384) \cdot\left(q(x) \cdot L^{4} / E_{m} I\right) \\
56.4373 \times 10^{-4}\end{array}$ & 0.3485 \\
\hline $\mathrm{CF}$ & $\begin{array}{l}\text { This work } \\
5.4255 \times 10^{-4}\end{array}$ & $\begin{array}{c}\text { Exact formula }[36,37] w_{\max }=(1 / 8) \cdot\left(q(x) \cdot L^{4} / E_{m} I\right) \\
5.4179 \times 10^{-4}\end{array}$ & 0.1392 \\
\hline
\end{tabular}

Note that $I=\left(b h^{3} / 12\right)$ is the moment of inertia $[36,37]$.

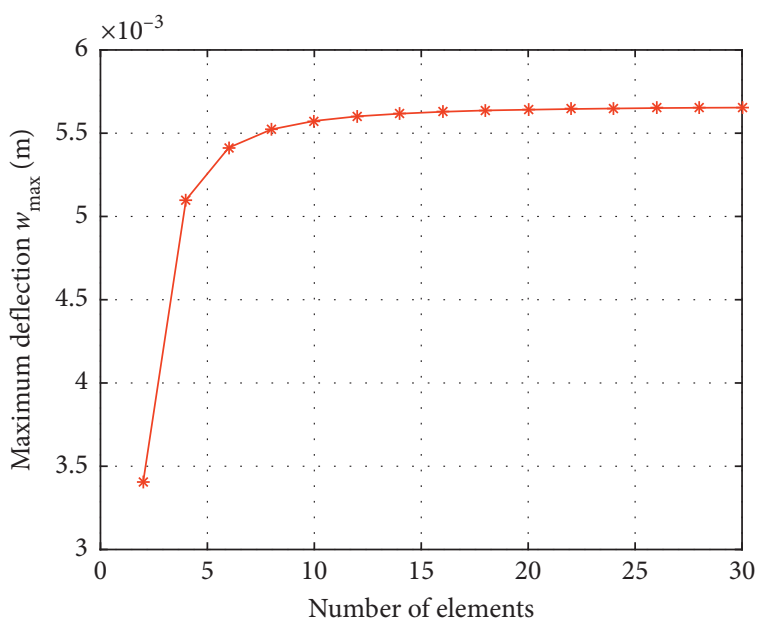

FIgURE 3: The convergence rate of maximum deflection of the SS beam.

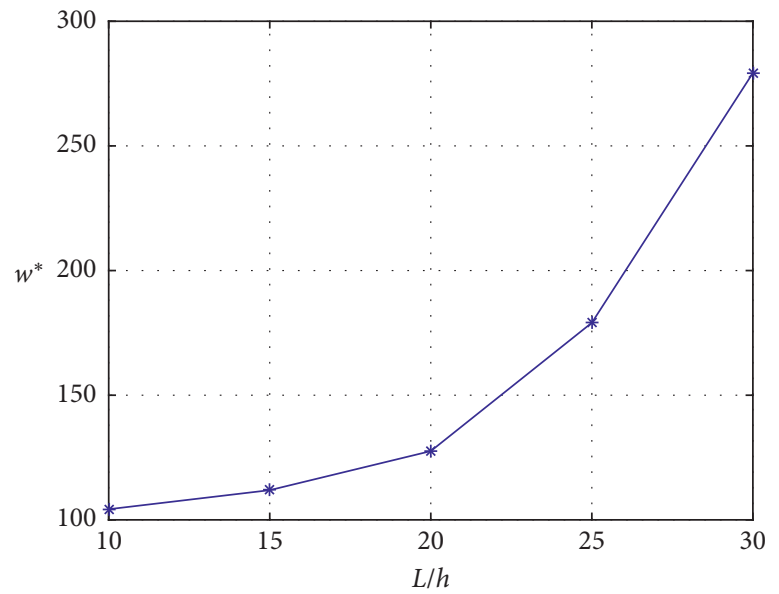

Figure 4: The dependence of the maximum deflection of the beam on the length-to-height ratio.

the ceramic decreases. Therefore, the beam becomes softer due to Young's modulus of the ceramic, which is higher than that of the metal. As a result, the maximum deflection of the beam is increased. In addition, it can be seen that Case 1 (red line) has a stronger effect on the deflection of the beam than Case 2 (blue line). This means that the material properties of 


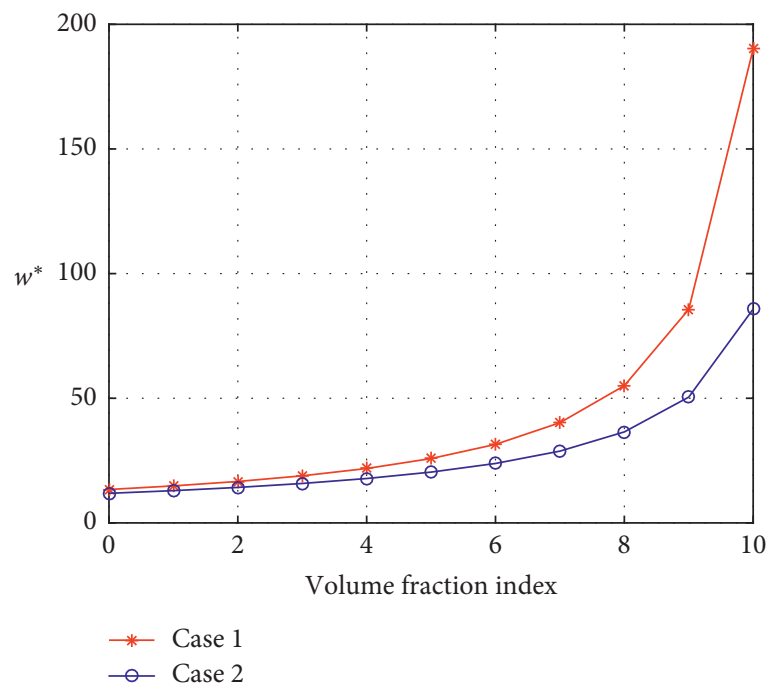

Figure 5: The maximum deflection of the beam depends on the volume fraction index.

the bottom layer have a stronger effect than those of the top layer. This can help engineers when designing these types of structures in practice.

3.2.3. Effect of Shear Coefficients. Next, the effect of shear coefficients on the static bending of this beam is investigated. Consider a four-meter fully simply supported beam with the geometrical and material properties as presented in the first investigation; volume fraction exponents of the top (layer 1) and the bottom (layer 3) layers $n_{1}=n_{3}=5$. Herein, two cases of shear coefficients are also considered:

(i) Case 1: the shear coefficient between the top and core layers remains constant $K_{12}=5.10^{7}\left(\mathrm{~N} / \mathrm{m}^{2}\right)$, while the shear coefficient between the core and bottom layers $K_{23}$ varies within a range of $5.10^{7}\left(\mathrm{~N} / \mathrm{m}^{2}\right)$ to $6.10^{8}\left(\mathrm{~N} / \mathrm{m}^{2}\right)$.

(ii) Case 2: the shear coefficient between the core and bottom layers remains constant $K_{23}=5.10^{7}\left(\mathrm{~N} / \mathrm{m}^{2}\right)$ while the shear coefficient between the top and core layers $K_{12}$ varies within a range of $5.10^{7}\left(\mathrm{~N} / \mathrm{m}^{2}\right)$ to $6.10^{8}\left(\mathrm{~N} / \mathrm{m}^{2}\right)$.

(iii) Case 3: the shear coefficient between the top and core layers remains constant $K_{12}=5.10^{7}\left(\mathrm{~N} / \mathrm{m}^{2}\right)$, while the one between the core and bottom layers varies between $5.10^{7}\left(\mathrm{~N} / \mathrm{m}^{2}\right)$ and $12.10^{11}\left(\mathrm{~N} / \mathrm{m}^{2}\right)$.

As indicated in equation (37), the beam's nondimensional maximum deflection is normalized. Figure 6 depicts the greatest deflections in the three situations.

Figure 6(a) presents the dependence of the maximum deflection of the beam on the shear coefficients. When the shear coefficients increase, the movements among layers tend to be removed. Therefore, the structure has become stronger. As a result, the maximum deflection of the beam decreases. Figure 6(b) also shows that when the shear coefficient reaches a sufficiently large value, the maximum deflection converges to a constant value. In other words, there are no relative movements between the layers of the beam.

Figure 7 presents the nondimensional stress distributions of the beam at the center cross section of the beam. Equation (38) normalizes normal and shear stress:

$$
\begin{aligned}
\sigma_{x}^{*} & =\frac{H}{q(x) L} \sigma_{x}\left(\frac{L}{2}\right), \\
\tau_{x z}^{*} & =\frac{H}{q(x) L} \tau_{x z}\left(\frac{L}{2}\right) .
\end{aligned}
$$

From Figure 7, it can be seen that the shear coefficients have a significant effect on the stress distributions of the beam. When the shear coefficients increase, the movements among layers tend to be removed. Therefore, the jumping stress tends to be removed as well. When the shear coefficients obtain a high value, the beam becomes a sandwich beam without relative movement. Because first-order shear deformation is used in this case, the shear stress is incorrectly described. To overcome this, it should use higher-order shear deformation theories.

The author next explores the effect of the shear connector distribution on the beam's static response. A four-meter cantilever beam with the same geometrical and material qualities as in the first research is studied; the volume fraction exponents of the top (layer 1) and bottom (layer 3) layers $n_{1}=n_{3}=5$. Shear coefficients $K_{12}=K_{23}=5 \cdot 10^{7}\left(\mathrm{~N} / \mathrm{m}^{2}\right)$. The length of the shear connector distribution $L_{\mathrm{sh}}$ changes to a range of 0 to $L$ as shown in Figure 8. Note that there is no delamination phenomenon in the section of the beam without shear connector based on the initial assumption.

The dependence of the deflection curve and the nondimensional maximum deflection of the beam on the $L_{s h}$ is shown in Figure 9.

The deflection of the beam is observed to decrease when the distribution length of the shear connector is increased. The basic reason is that as the number of shear connectors between layers rises, the structure's rigidity rises. 


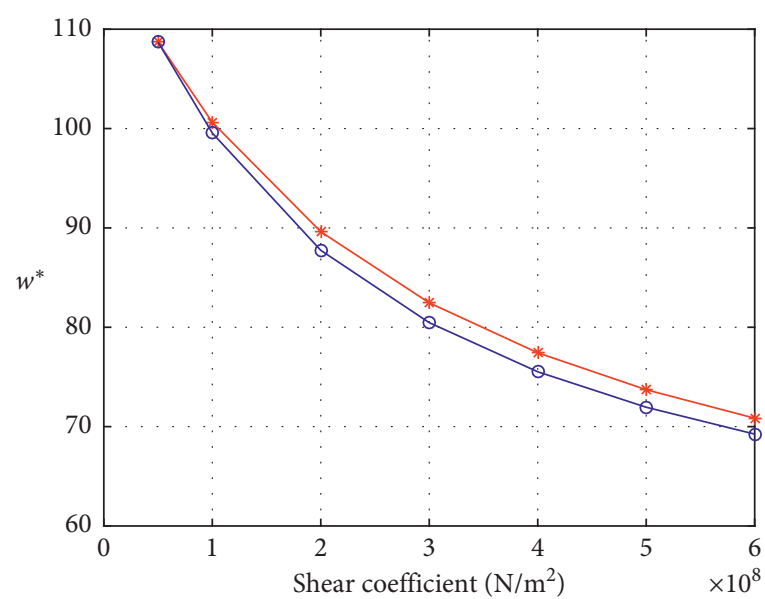

* Case 1

$\rightarrow$ Case 2

(a)

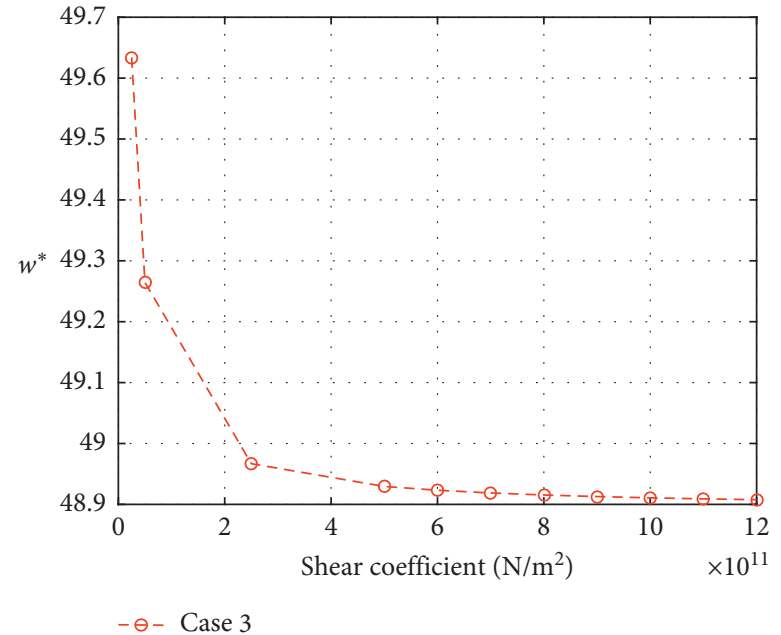

(b)

Figure 6: The dependence of the maximum deflection of the beam on the shear coefficient.

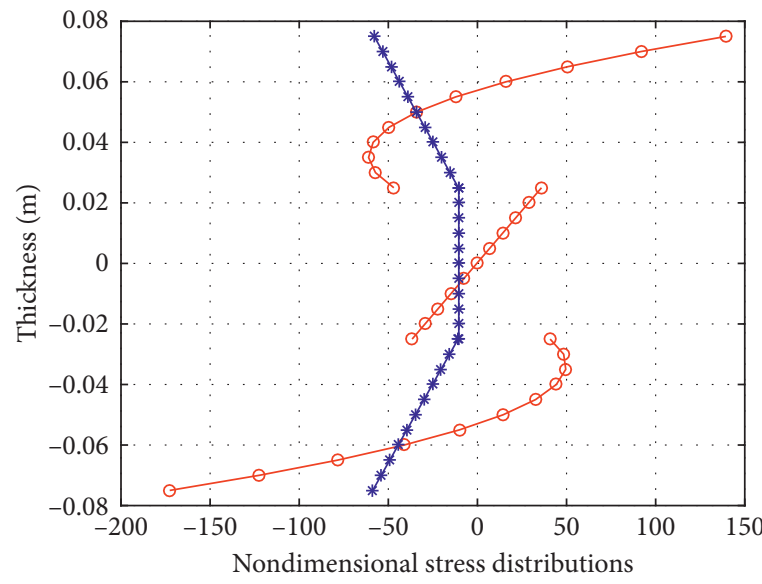

$\multimap K_{12}=K_{23}=5.10^{7}\left(\mathrm{~N} / \mathrm{m}^{2}\right)$

(a)

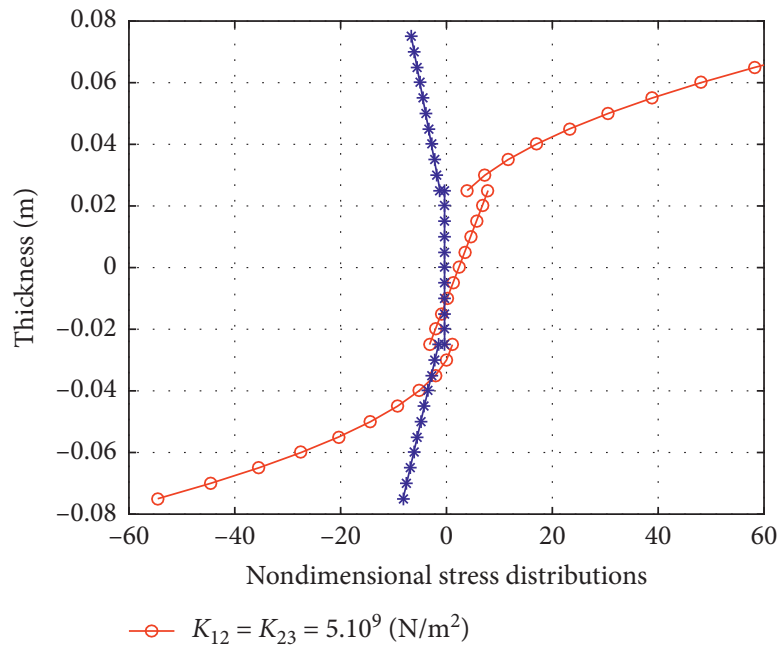

(c)

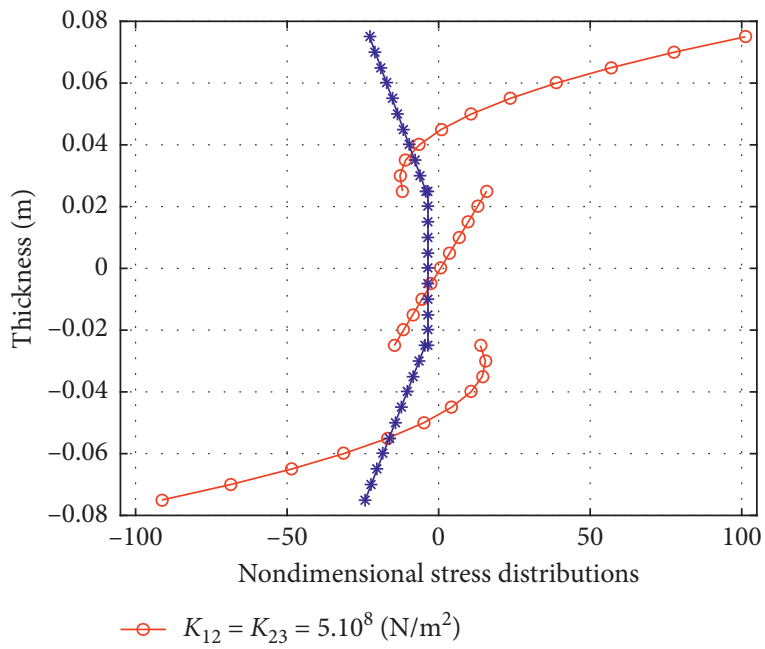

(b)

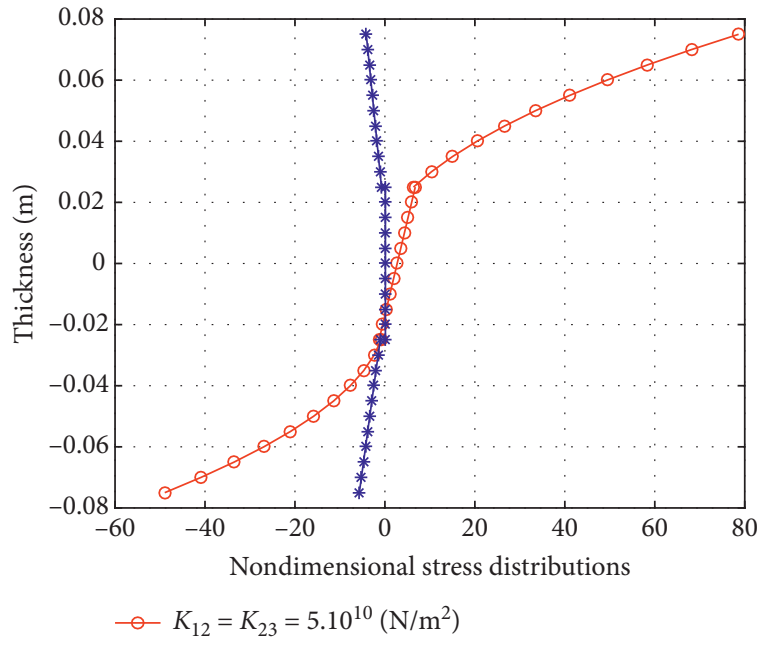

(d)

Figure 7: The stress distributions depend on the shear coefficients. 


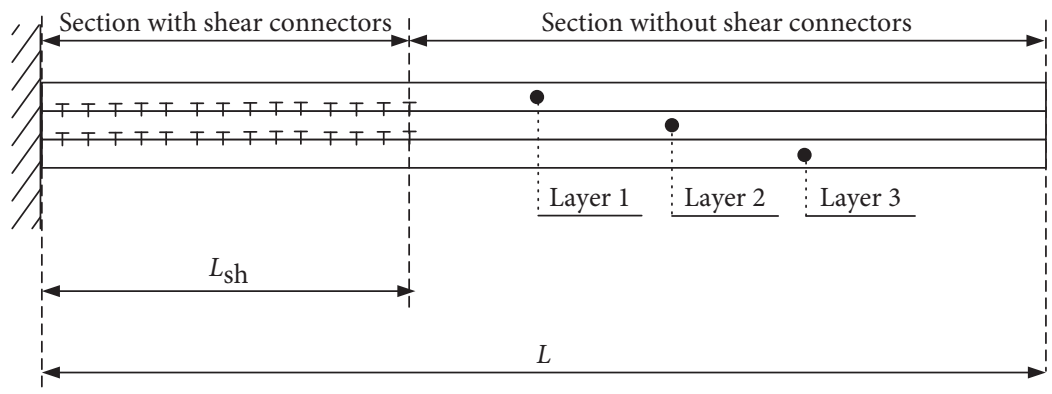

FIGURE 8: The length of the shear connector distribution.
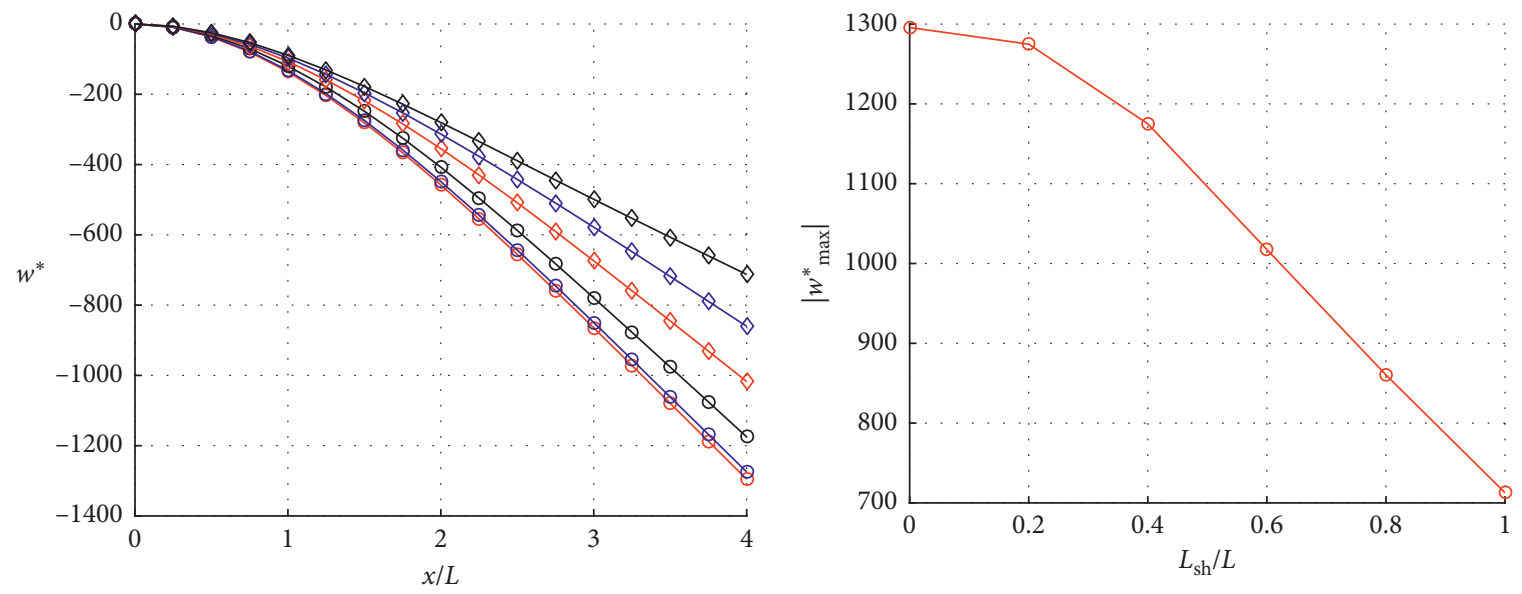

$$
\begin{aligned}
& \multimap L_{\mathrm{sh}} / L=0 \quad \neg L_{\mathrm{sh}} / L=0.6 \\
& \bigcirc L_{\mathrm{sh}} / L=0.2 \quad \neg L_{\mathrm{sh}} / L=0.8 \\
& \multimap L_{\mathrm{sh}} / L=0.4 \quad \neg L_{\mathrm{sh}} / L=1.0
\end{aligned}
$$

(a)

(b)

Figure 9: The dependence of the deflection curve and nondimensional maximum deflection of the CF beam on the length of the shear connector distribution.

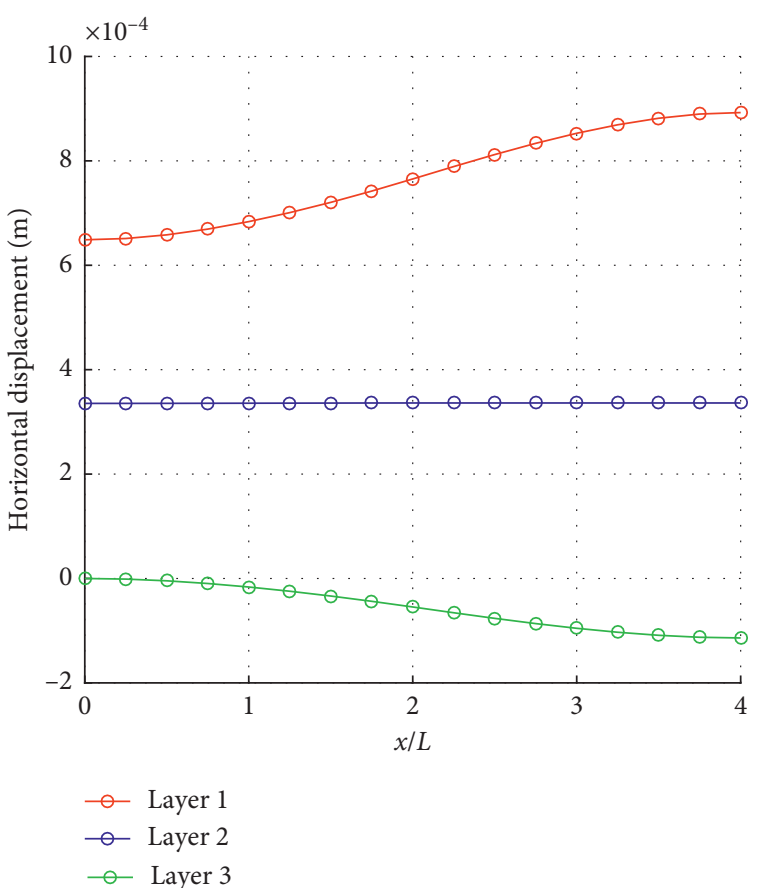

(a)

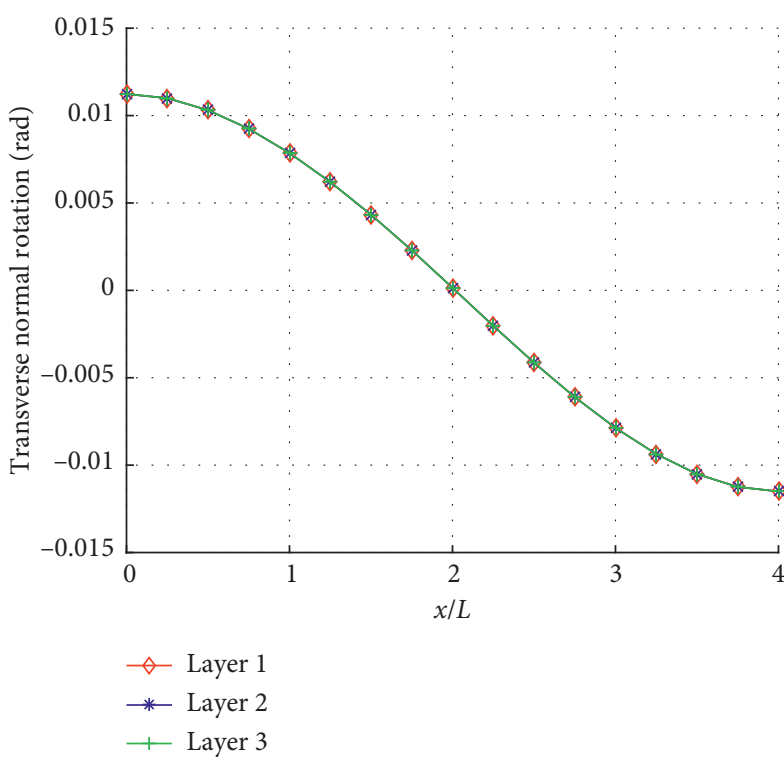

(b)

FIgURE 10: The horizontal displacement and transverse normal rotation of three layers of the SS beam $\left(L_{s h} / L\right)=0.5$. 


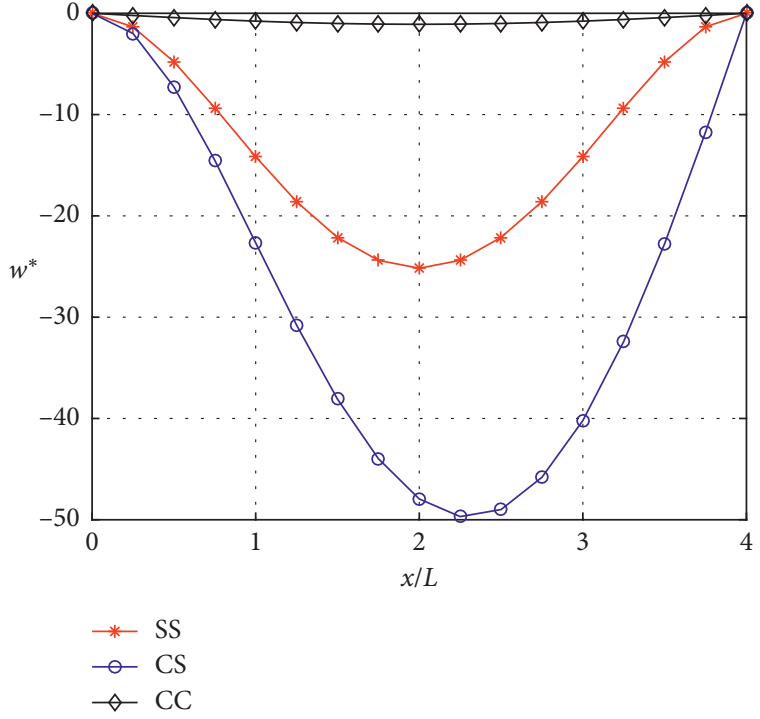

(a)

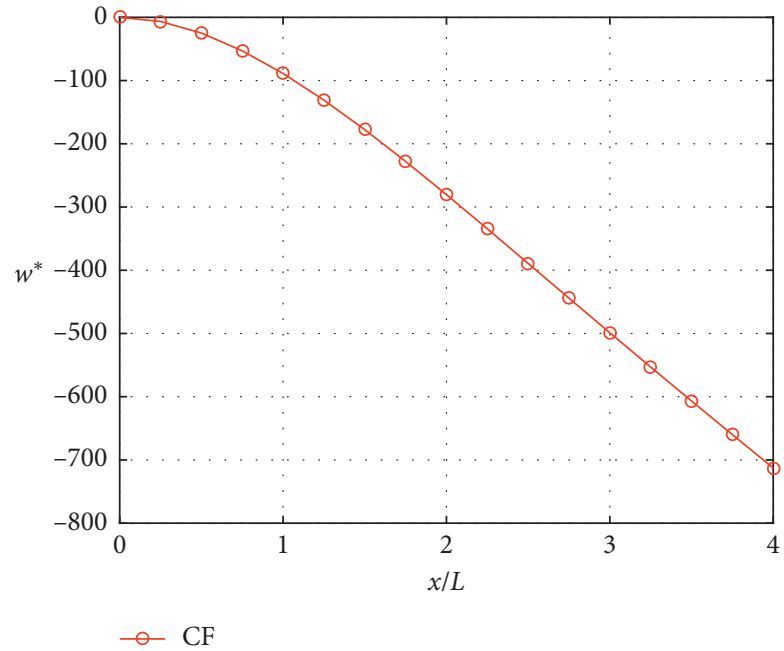

(b)

FIgURE 11: The dependence of the deflection on the boundary conditions.

Figure 10 presents the horizontal displacement of three layers of the SS beam in the case of $\left(L_{s h} / L\right)=0.5$.

It has been discovered that, in the beam section without shear connectors between layers, the absolute value of horizontal displacement of layers 1 and 3 has increased. For the core layer, this value is almost unchanged along the beam. For the transverse normal rotation, the values are the same for all three component layers.

3.2.4. Effect of Boundary Conditions. Finally, the effect of the boundary condition on the static response of the beam is examined. Four boundary conditions are considered:

(i) Beam fully clamped: CC

(ii) Simply supported beam: SS

(iii) One side is clamped, and the other one is simply supported: CS

(iv) One side is clamped, and the other one is free: CF

A four-meter beam with the geometrical and material properties is presented in the first investigation; volume fraction exponents of the top (layer 1) and the bottom (layer 3) layers $n_{1}=n_{3}=5$. The nondimensional deflection is defined as shown in equation (37). The static bending response is depicted in Figure 11.

It can be seen that the boundary conditions have a strong effect on the static bending of the beam. The CF beam has the highest maximum deflection, followed by the CS, SS, and CC beams. The simple reason is that the more the degrees of freedom are constrained, the stronger the structure becomes.

\section{Conclusions}

Static bending analysis of symmetric FGM sandwich beams with shear connections was carried out in this study. Timoshenko's well-known first-order shear deformation beam theory is used to generate finite element formulations. Some new points may be summed up as follows as a result of the numerical investigation:

(i) As the length of the beam rises, the structure gets softer, increasing the beam's maximum deflection.

(ii) The volume fraction exponents of the top and bottom layers have a strong influence on the static response of the beam. When the volume fraction exponent increases, the proportion of metal in the beam increases. Therefore, the beam becomes softer due to Young's modulus of ceramic, which is higher than that of metal. Therefore, the maximum deflection of the beam increases.

(iii) Shear coefficients are also highly significant in the beam's static bending response. Because the shear coefficients rise, the relative motions across layers will be eliminated. The static bending response converges to constant values when the shear coefficients reach a large value. In addition, the distribution of shear connectors also greatly affects the static response of the beam. As the shear distribution length increases, the stiffness of the beam increases, leading to a decrease in deflection.

(iv) Finally, boundary circumstances have a significant impact on beam bending. The structure grows stronger as more degrees of freedom are restricted.

The numerical results of this work are extremely valuable, since they help us better understand the mechanical behavior of plate structures formed of functionally graded materials and connected by shear connectors. The findings can also be used in engineering practice when studying, calculating, and constructing structures of this sort. 


\section{Appendix}

$$
\begin{aligned}
& {[A]=\left[\begin{array}{ccc}
\int_{-h_{1} / 2}^{h_{1} / 2} E^{(1)}\left(z^{(1)}\right) \mathrm{d} z^{(1)} & 0 & 0 \\
0 & E^{(2)} \cdot h_{2} & 0 \\
0 & 0 & \int_{-h_{3} / 2}^{h_{3} / 2} E^{(3)}\left(z^{(3)}\right) \mathrm{d} z^{(3)}
\end{array}\right],} \\
& {[B]=\left[\begin{array}{ccc}
\int_{-h_{1} / 2}^{h_{1} / 2} E^{(1)}\left(z^{(1)}\right) \cdot z^{(1)} \cdot \mathrm{d} z^{(1)} & 0 & 0 \\
0 & 0 & 0 \\
0 & 0 \int_{-h_{3} / 2}^{h_{3} / 2} E^{(3)}\left(z^{(3)}\right) \cdot z^{(3)} \cdot \mathrm{d} z^{(3) 0}
\end{array}\right] \text {, }} \\
& {[D]=\left[\begin{array}{ccc}
\int_{-h_{1} / 2}^{h_{1} / 2} E^{(1)}\left(z^{(1)}\right) \cdot z^{(1)} \cdot z^{(1)} \cdot \mathrm{d} z^{(1)} & 0 & 0 \\
0 & E^{(2)} \cdot \frac{h_{2}^{3}}{12} & 0 \\
0 & 0 & \int_{-h_{3} / 2}^{h_{3} / 2} E^{(3)}\left(z^{(3)}\right) \cdot z^{(3)} \cdot z^{(3)} \cdot \mathrm{d} z^{(3)}
\end{array}\right] \text {, }} \\
& {[\widehat{A}]=\left[\begin{array}{ccc}
k \int_{-h_{1} / 2}^{h_{1} / 2} \frac{E^{(1)}\left(z^{(1)}\right)}{2\left(1+\mu^{(1)}\left(z^{(1)}\right)\right)} \cdot \mathrm{d} z^{(1)} & 0 & 0 \\
0 & \frac{k \cdot E^{(2)} \cdot h_{2}}{2\left(1+\mu^{(2)}\right)} & 0 \\
0 & 0 & k \int_{-h_{3} / 2}^{h_{31} / 2} \frac{E^{(3)}\left(z^{(3)}\right)}{2\left(1+\mu^{(3)}\left(z^{(3)}\right)\right)} \cdot \mathrm{d} z^{(3)}
\end{array}\right] \text {, }} \\
& {[N]=\left[\begin{array}{cccccccccccccc}
N_{1} & 0 & 0 & 0 & 0 & 0 & 0 & N_{2} & 0 & 0 & 0 & 0 & 0 & 0 \\
0 & N_{1} & 0 & 0 & 0 & 0 & 0 & 0 & N_{2} & 0 & 0 & 0 & 0 & 0 \\
0 & 0 & N_{1} & 0 & 0 & 0 & 0 & 0 & 0 & N_{2} & 0 & 0 & 0 & 0 \\
0 & 0 & 0 & N_{1} & 0 & 0 & 0 & 0 & 0 & 0 & N_{2} & 0 & 0 & 0 \\
0 & 0 & 0 & 0 & N_{1} & 0 & 0 & 0 & 0 & 0 & 0 & N_{2} & 0 & 0 \\
0 & 0 & 0 & 0 & 0 & N_{1} & 0 & 0 & 0 & 0 & 0 & 0 & N_{2} & 0 \\
0 & 0 & 0 & 0 & 0 & 0 & N_{1} & 0 & 0 & 0 & 0 & 0 & 0 & N_{2}
\end{array}\right],} \\
& {\left[B_{1}\right]=\sum_{i=1}^{2}\left[\begin{array}{ccccccc}
\frac{\partial N_{i}}{\partial x} & 0 & 0 & 0 & 0 & 0 & 0 \\
0 & \frac{\partial N_{i}}{\partial x} & 0 & 0 & 0 & 0 & 0 \\
0 & 0 & \frac{\partial N_{i}}{\partial x} & 0 & 0 & 0 & 0
\end{array}\right] \text {, }} \\
& {\left[B_{2}\right]=\sum_{i=1}^{2}\left[\begin{array}{ccccccc}
0 & 0 & 0 & 0 & \frac{\partial N_{i}}{\partial x} & 0 & 0 \\
0 & 0 & 0 & 0 & 0 & \frac{\partial N_{i}}{\partial x} & 0 \\
0 & 0 & 0 & 0 & 0 & 0 & \frac{\partial N_{i}}{\partial x}
\end{array}\right] \text {, }}
\end{aligned}
$$

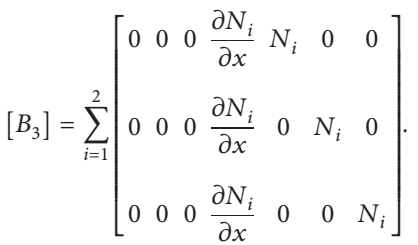




\section{Data Availability}

No data were used to support this study.

\section{Conflicts of Interest}

The authors declare no conflicts of interest.

\section{Acknowledgments}

This study has been funded by the Scientific Research Support Foundation of Le Quy Don Technical University, under code: 2021.16.

\section{References}

[1] M. Koizumi and M. Niino, "Overview of FGM research in Japan,” MRS Bulletin, vol. 20, no. 1, pp. 19-21, 1995.

[2] T. Jun, "Development and application of functionally gradient materials," in Proceedings of the International Conference on Industrial Control and Electronics Engineering, pp. 1022-1025, Hangzhou, China, March 2012.

[3] I. Shiota and Y. Miyamoto, Functionally Graded Materials, Elsevier Science 1996, Amsterdam, Netherlands, 1996.

[4] Y. Li, Z. Feng, L. Hao et al., "A review on functionally graded materials and structures via additive manufacturing: from multi-scale design to versatile functional properties," $A d$ vanced Materials Technologies, vol. 5, no. 6, Article ID 1900981, 2020.

[5] L. Weikai and H. Baohong, "Research and application of functionally gradient materials," Materials Science and Engineering, vol. 394, Article ID 022065, 2018.

[6] I. Bairamov and S. Kotz, "Dependence structure and symmetry of Huang-Kotz FGM distributions and their extensions," Metrika, vol. 56, no. 1, pp. 55-72, 2002.

[7] A. Baghlani, M. Khayat, and S. M. Dehghan, "Free vibration analysis of FGM cylindrical shells surrounded by Pasternak elastic foundation in thermal environment considering fluidstructure interaction," Applied Mathematical Modelling, vol. 78, pp. 550-575, 2020.

[8] V. T. Do, H. D. Doan, V. M. Phung, and S. T. Nguyen, "Finite element modelling for free vibration response of cracked stiffened FGM plates," Vietnam Journal of Science and Technology, vol. 58, no. 1, pp. 119-129, 2020.

[9] H. N. Vu, H. N. Nguyen, V. V. Pham, N. K. Dang, V. T. Do, and V. M. Phung, "A new efficient modified first-order shear model for static bending and vibration behaviors of two-layer composite plate," Advances in Civil Engineering, vol. 2019, Article ID 6814367, 17 pages, 2019.

[10] T. T. Tran, N. H. Nguyen, D. V. Do, P. V. Minh, and N. D. Duc, "Bending and thermal buckling of unsymmetric functionally graded sandwich beams in high-temperature environment based on a new third-order shear deformation theory," Journal of Sandwich Structures and Materials, pp. 1-25, 2019.

[11] H. N. Nguyen, T. C. Tan, D. T. Luat, V. D. Phan, D. V. Thom, and P. V. Minh, "Research on the buckling behavior of functionally graded plates with stiffeners based on the thirdorder shear deformation theory," Materials (Basel, Switzerland), vol. 12, no. 8, 2019.

[12] D. Lam and E. El-Lobody, "Behavior of headed stud shear connectors in composite beam," Journal of Structural Engineering, vol. 131, no. 1, pp. 96-107, 2005.
[13] C.-S. Shim, P.-G. Lee, and T.-Y. Yoon, "Static behavior of large stud shear connectors," Engineering Structures, vol. 26, no. 12, pp. 1853-1860, 2004.

[14] M. R. Salari, E. Spacone, P. B. Shing, and D. M. Frangopol, "Nonlinear analysis of composite beams with deformable shear connectors," Journal of Structural Engineering, vol. 124, no. 10, pp. 1148-1158, 1998.

[15] N. Gattesco and E. Giuriani, "Experimental study on stud shear connectors subjected to cyclic loading," Journal of Constructional Steel Research, vol. 38, no. 1, pp. 1-21, 1996.

[16] T. M. Roberts and O. Dogan, "Fatigue of welded stud shear connectors in steel-concrete-steel sandwich beams," Journal of Constructional Steel Research, vol. 45, no. 3, pp. 301-320, 1998.

[17] X. Weichen, D. Min, W. Hua, and L. Ziwen, "Static behavior and theoretical model of stud shear connectors," Journal of Bridge Engineering, vol. 13, no. 6, pp. 623-634, 2008.

[18] E. Baran and C. Topkaya, "An experimental study on channel type shear connectors," Journal of Constructional Steel Research, vol. 74, pp. 108-117, 2012.

[19] L. Li, X. Li, and Y. Hu, "Free vibration analysis of nonlocal strain gradient beams made of functionally graded material," International Journal of Engineering Science, vol. 102, pp. 77-92, 2016.

[20] H. Hachemi, A. Bousahla, K. Abdelhakim et al., "Bending analysis of functionally graded plates using a new refined quasi-3D shear deformation theory and the concept of the neutral surface position," Steel and Composite Structures, vol. 39, pp. 51-64, 2021.

[21] S. Chikr, K. Abdelhakim, A. Bousahla et al., "A novel fourunknown integral model for buckling response of FG sandwich plates resting on elastic foundations under various boundary conditions using Galerkin's approach," Geomechanics and Engineering, vol. 21, pp. 471-487, 2020.

[22] A. Menasria, K. Abdelhakim, A. Bousahla et al., "A four unknown refined plate theory for dynamic analysis of FGsandwich plates under various boundary conditions," Steel and Composite Structures, vol. 36, pp. 355-367, 2020.

[23] V. H. Nam, N. H. Nam, P. V. Vinh, D. N. Khoa, D. V. Thom, and P. V. Minh, "A new efficient modified first-order shear model for static bending and vibration behaviors of two-layer composite plate," Advances in Civil Engineering, vol. 2019, Article ID 6814367, 17 pages, 2019.

[24] L. R. D. Santos, H. D. S. Cardoso, R. B. Caldas, and L. F. Grilo, "Finite element model for bolted shear connectors in concrete-filled steel tubular columns," Engineering Structures, vol. 203, Article ID 109863, 2020.

[25] R. Vetturayasudharsanan, G. Balaji, P. Balamurugan, and R. Dineshkumar, "Analytical study of triangular perfobond shear connectors," Innovative Infrastructure Solutions, vol. 6, no. 2, p. 115, 2021.

[26] X. Q. Xu, Z. W. Yu, D. Y. He, H. M. Tan, and S. W. Zeng, Effect of Concrete Cracks on the Corrosion of Stud Shear Connectors, CRC Press, Boca Raton, FL, USA, 2021.

[27] D. Arévalo, L. Hernández, C. Gómez et al., "Structural performance of steel angle shear connectors with different orientation," Case Studies in Construction Materials, vol. 14, Article ID e00523, 2021.

[28] H. Hirane, M. O. Belarbi, M. Houari, and A. Tounsi, "On the layerwise finite element formulation for static and free vibration analysis of functionally graded sandwich plates," Engineering with Computers, p. 3, 2021.

[29] T. P. Vo, H.-T. Thai, T.-K. Nguyen, A. Maheri, and J. Lee, "Finite element model for vibration and buckling of 
functionally graded sandwich beams based on a refined shear deformation theory," Engineering Structures, vol. 64, pp. 1222, 2014.

[30] N. Wattanasakulpong, B. Gangadhara Prusty, and D. W. Kelly, "Thermal buckling and elastic vibration of thirdorder shear deformable functionally graded beams," International Journal of Mechanical Sciences, vol. 53, no. 9, pp. 734-743, 2011.

[31] H.-S. Shen and Z.-X. Wang, "Nonlinear analysis of shear deformable FGM beams resting on elastic foundations in thermal environments," International Journal of Mechanical Sciences, vol. 81, pp. 195-206, 2014.

[32] J. N. Reddy, "Analysis of functionally graded plates," International Journal for Numerical Methods in Engineering, vol. 47, no. 1-3, pp. 663-684, 2000.

[33] A. M. Zenkour, "Generalized shear deformation theory for bending analysis of functionally graded plates," Applied Mathematical Modelling, vol. 30, no. 1, pp. 67-84, 2006.

[34] T. V. Do, T. Q. Bui, T. T. Yu, D. T. Pham, and C. T. Nguyen, "Role of material combination and new results of mechanical behavior for FG sandwich plates in thermal environment," Journal of Computational Science, vol. 21, pp. 164-181, 2017.

[35] E. Isaac, "Who developed the so-called Timoshenko beam theory?" Mathematics and Mechanics of Solids, vol. 25, no. 1, pp. 97-116, 2019.

[36] R. K. Bansal, A Textbook of Strength of Materials, Laxmi Publication (P) LTD, New Delhi, India, 2009.

[37] R. S. Khurmi, Strength of Material: Mechanics of Solids, S. Chand Publishing, New Delhi, India, 2006. 